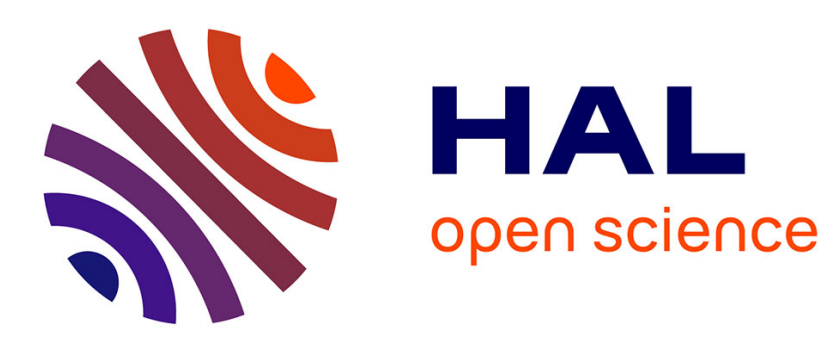

\title{
TEMPERATURE RISES DURING HIGH RATE DEFORMATION OF POLYMERS
}

\author{
P. Dawson, G. Swallowe, Z. Xinwu
}

\section{To cite this version:}

P. Dawson, G. Swallowe, Z. Xinwu. TEMPERATURE RISES DURING HIGH RATE DEFORMATION OF POLYMERS. Journal de Physique IV Proceedings, 1991, 01 (C3), pp.C3-701-C3-706. 10.1051/jp4:1991398 . jpa-00250544

\section{HAL Id: jpa-00250544 https://hal.science/jpa-00250544}

Submitted on 1 Jan 1991

HAL is a multi-disciplinary open access archive for the deposit and dissemination of scientific research documents, whether they are published or not. The documents may come from teaching and research institutions in France or abroad, or from public or private research centers.
L'archive ouverte pluridisciplinaire HAL, est destinée au dépôt et à la diffusion de documents scientifiques de niveau recherche, publiés ou non, émanant des établissements d'enseignement et de recherche français ou étrangers, des laboratoires publics ou privés. 
TEMPERATURE RISES DURING HIGH RATE DEFORMATION OF POLYMERS

\author{
P.C. DAWSON, G.M. SWALLOWE and Z. XINWU \\ Department of Physics, Loughborough University of Technology, \\ Loughborough, GB-Leicestershire LEI1 3TU, Great-Britain
}

\begin{abstract}
Résumé: Des expériences pour mesurer la réponse contrainte-déformation et ílévation de température à la fois en volume et localement ont été effectuées sur une large gamme de polymères à des vitesses de $10^{2}$ à $10^{3} \mathrm{~s}^{-1}$. Lcs paramètres de décomposition et les chaleurs spécifiques ont été déterminées par calorimétrie différentielle. Les résultats obtenus suggèrent qu'une décomposition thermique significative peut se produire en avant des fissures dans certains matériaux et dans tous les cas, l'échauffement conduit à des déviations de la courbe isotherme contraintedéformation vraies.
\end{abstract}

Abstract - Experiments to measure stress-strain response and both bulk and localised temperature rises have been carried out on a wide range of polymers at strain rates of $10^{2}-10^{3} \mathrm{~s}^{-1}$. Decomposition parameters and specific heats have been determined by Differential Scanning Calorimetry. Results obtained suggest significant thermal decomposition may occur ahead of running cracks in some materials and in all cases heating leads to deviations from a true isothermal stress-strain curve.

\title{
1. INTRODUCTION
}

In recent years attention has been drawn to the effect of temperature rises produced during the high rate deformation of materials on experimental stress-strain curves $/ 1 \%$. When tests are carried out to large strains the increased sample temperature may cause the flow stress at the higher strain rates to fall below the quasi-static values /1/. These bulk temperature rises are to be distinguished from any localised temperature rises due to such processes as adiabatic shear or cracking/crazing and are due to the adiabatic nature of the deformation process at high strain rates. Frost and Ashby $/ 2 /$ have derived an expression for the critical strain rate above which adiabatic behaviour is expected. Their (approximate) equation

$$
\dot{\epsilon}_{A}=\frac{4 n K}{R^{2}\left[\frac{\partial \sigma y}{\partial T}\right]_{\epsilon, \dot{\epsilon}}}
$$

yields a value of $\dot{\epsilon}$ of $0.2 \mathrm{~s}^{-1}$ for polycarbonate using typical values of $\mathrm{R}$ of $3 \mathrm{~mm} \mathrm{~K}=0.2$ $\mathrm{Wm}^{-1}{ }^{\circ} \mathrm{C}^{-1}$,

$$
\frac{\partial \sigma \mathrm{y}}{\partial \mathrm{T}}=0.39 \mathrm{MPa}{ }^{\circ} \mathrm{C}^{-1}\left(\dot{\epsilon}=10^{3} \mathrm{~S}^{-1} / 3 /\right) \text { and } \mathrm{n}=\sim 1 \text { from our results. }
$$


This is typical of many polymers and is lower than the values for metals due to the low heat conductivity of polymers. The heating effect is particularly important for polymers since they show a much greater temperature dependence of mechanical properties than metals. Thus a stress-strain curve obtained at a given (high) strain rate will, in fact, be a 'composite' curve of sections from an (infinite) series of stress-strain curves each of a higher temperature than its predecessor. This may not actually be a practical disadvantage since the material when in service will undergo a similar temperature increment to the test sample. It is however a problem if experimentally determined stress-strain curves are to be used as data for the production of constitutive models of the materials.

The above considerations apply to bulk temperature effects only. During localised deformation processes such as adiabatic shear, crazing and cracking, stored elastic energy is dissipated in a very small region and thus very high, if short lived, temperatures may arise 14,5/. Since these temperature increases occur during material failure they are of little importance in the description of the pre-failure material properties but may, of course, be of major importance in determining the mode of failure and its dynamics. This paper describes the initial results of a research programme into temperature rises, both bulk and localised, produced in a wide range of polymers at strain rates $\sim 10^{2}-10^{3} \mathrm{~s}^{-1}$.

\section{EXPERIMENTAL}

All the high strain rate work described in this paper was carried out on a specially constructed instrumented drop weight machine broadly similar to that described in Heavens and Field $/ 6 /$. Samples were held between hardened steel rollers and impacted by a $3.8 \mathrm{~kg}$ weight falling freely under gravity. Typical impact velocity were $\sim 2.5 \mathrm{~m} / \mathrm{s}$ giving an initial strain rate of $\sim 600 \mathrm{~s}^{-1}$. Although the weight's velocity rapidly decreases during impact the decreasing thickness of the sample almost compensates for the reduction in weight velocity to yield a nearly constant strain rate during the test. (Figure 1).

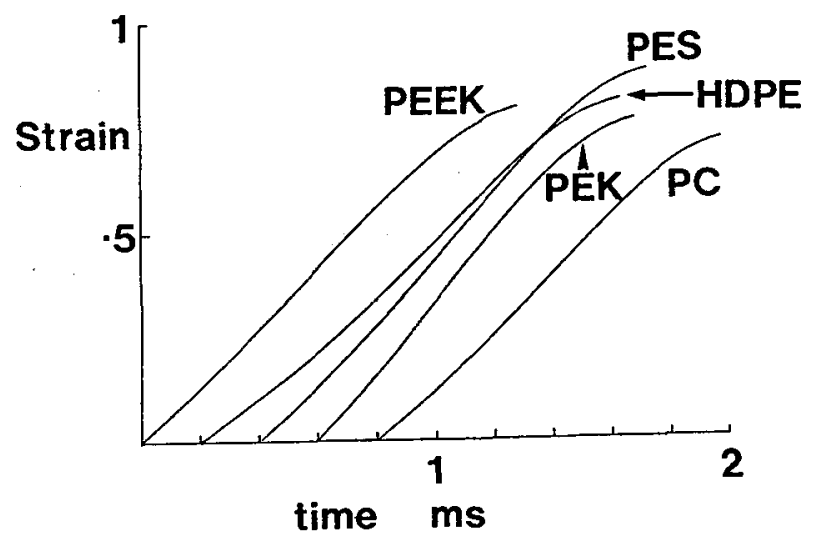

Figure 1 Example of stress-time curves for different materials.

Traces have been offset by $0.2 \mathrm{~ms}$ increments.

Bulk temperature rise on high strain rate compression was measured by drilling a small ( $0.25 \mathrm{~mm}$ ) hole in the side of each specimen. $0.2 \mathrm{~mm}$ nickel-chromium/nickel-aluminium 
thermocouple wire, with its end welded to form a small sphere, was inserted into the hole so that the sphere was at the centre of the specimen. The thermocouple was connected to a storage oscilloscope and the resulting signal used to evaluate the temperature rise. Specimens were compressed in the normal way using the drop-weight impact machine described above and traces of temperature rise versus time recorded. The thermocouples used were the same as described in Dixon and Parry /7/ with a time response of $\sim 400 \mu \mathrm{s}$. Since the drop weight impact durations were typically 1-2 ms and the low thermal conductivity of the polymers would reduce losses due to heat conduction to negligible amounts the recorded peak thermocouple temperature will be a good representation of the actual peak sample temperature. A typical thermocouple output/time trace is illustrated in figure 2 and a polycarbonate sample with thermocouple in place in figure 3 .

Values of specific heats and thermal decomposition parameters have been calculated using a Mettler DSC 20 system to obtain the necessary thermal date.

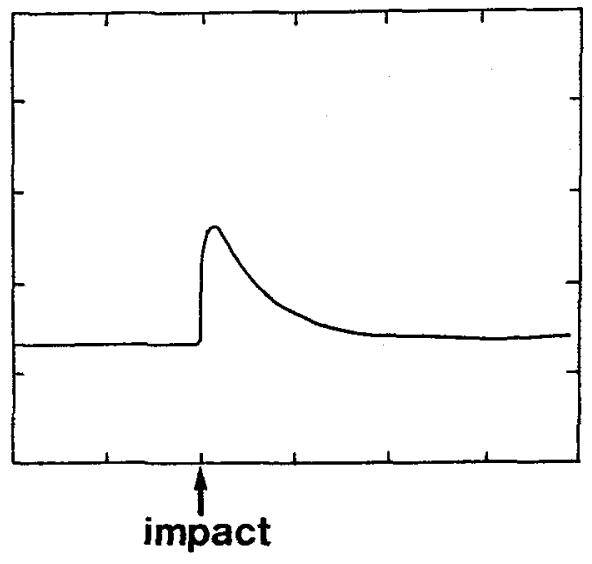

Figure 2 Thermocouple output-time trace for impact on a PEK sample. Vertical scale $50^{\circ} \mathrm{C} /$ division; horizontal scale 5 s/division.

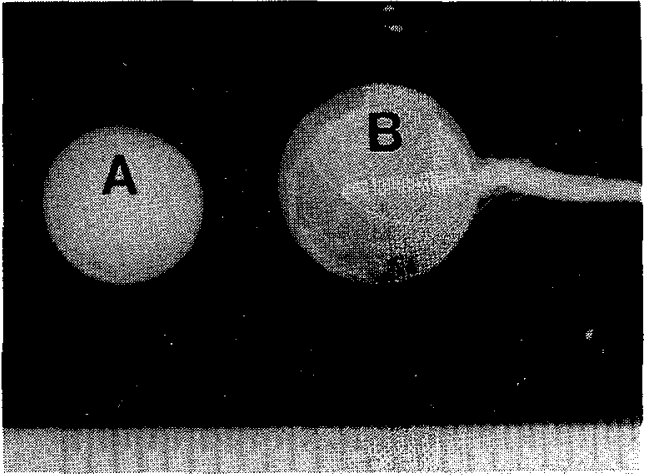

Figure 3 Photograph of PC samples: A, initial rise; $B$, deformed sample with thermocouple in place. Scale of $\mathrm{mm}$ and $1 / 2 \mathrm{~mm}$.

\section{MATERIALS}

The polymers examined were Polypenco high impact polyethylene (HDPE) rod 80 , polypropylene (PP) rod from Goodfellow Advanced Materials, Polypenco nylon 66 annealed rod QCR 011276, polycarbonate (PC) rod from Goodfellow Advanced materials, ICI "Victrex" polyetheretherketone (PEEK) 380G plaque, ICI "Victrex" polyetherketone (PEK) $220 \mathrm{G}$ plaque, and ICI "Victrex" polyethersulphone (PES) $4100 \mathrm{G}$ plaque.

All tests were carried out on $6 \mathrm{~mm}$ diameter $3-4 \mathrm{~mm}$ high discs which were machined from the above materials.

\section{RESULTS}

The data collected during the high strain rate tests is summarised in Figure 4. Calculations of expected temperature rises were made by equating the plastic work done on samples (by integration of the stress-strain curves) to increases in thermal energy using experimentally measured specific heats. These results together with experimentally measured maximum 
temperatures are set out in Table 1. The thermocouple values represent results from unfractured samples. Since the thermocouple itself tends to break before the sample fractures calculated temperature rises for samples which fracture are in general higher than measured values.

In order to "correct" stress strain curves to isothermal ones at a given strain rate a procedure similar to that used in /7/ may be employed. Work to obtain the required data is presently in progress but rough estimates of the stress "correction" required $\Delta \sigma$ for a given strain $\epsilon$ may be made by putting

$$
\Delta \sigma=\frac{\partial \sigma}{\partial \mathrm{T}} \Delta \mathrm{T}
$$

and evaluating $\triangle T$ from the stress-strain curves. Modified stress strain curves for $P C$ and HDPE using data from /3/ for $\frac{\partial \sigma}{\partial T}$ are illustrated in. Figure 5. It can be seen that for HDPE $\partial T$

relatively little effect is expected for strains of less than 0.5 but noticeable divergence of the experimental and isothermal curves for PC occur almost from the yield point. This is not unexpected since the stress levels and hence the temperature rises are higher in PC.

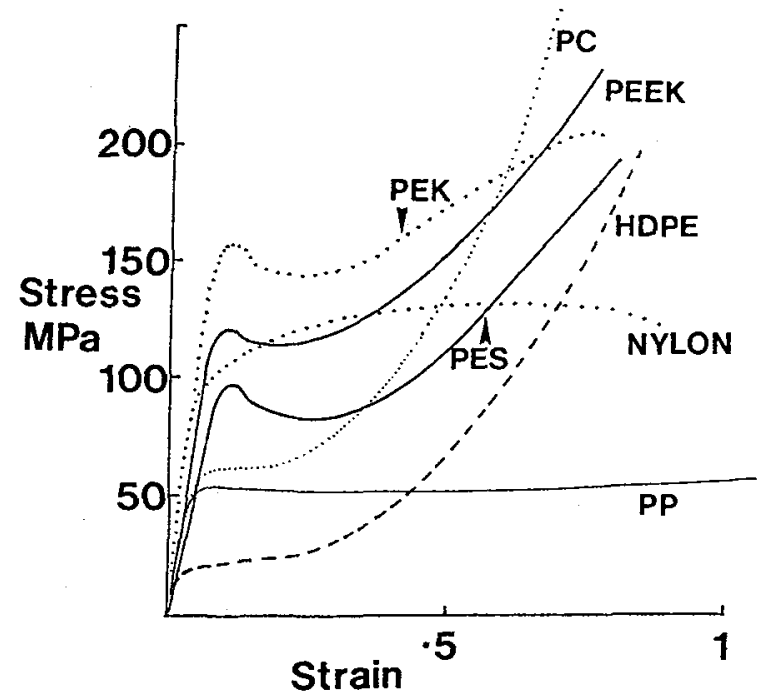

Figure 4 Stress-strain curves for the materials tested at $\dot{\epsilon} \sim 7 \times 10^{2}$

Results for temperature rises at the tips of cracks in fracturing samples obtained by the previously described Heat Sensitive Film technique /5/ are set out in Table 1. Table 2 gives the polymer decomposition parameters calculated by the ASTM method /8/ and the resulting fractional decomposition rates at the peak temperatures. Decomposition rates are estimated from

$$
\frac{\mathrm{dx}}{\mathrm{dt}}=\mathrm{A} \mathrm{e}^{-\mathrm{E} / \mathrm{RT}} \mathrm{f}(\mathrm{x})
$$

with $x$ the fractional decomposition rate and $f(x)$ some function of the fraction of sample 
decomposed which will be typically $=1$ for $\mathrm{x}$ small. The "film" bulk temperature rises are from reference $/ 5 /$ and represent estimates of temperatures achieved at very large strains of up to 1.5 .

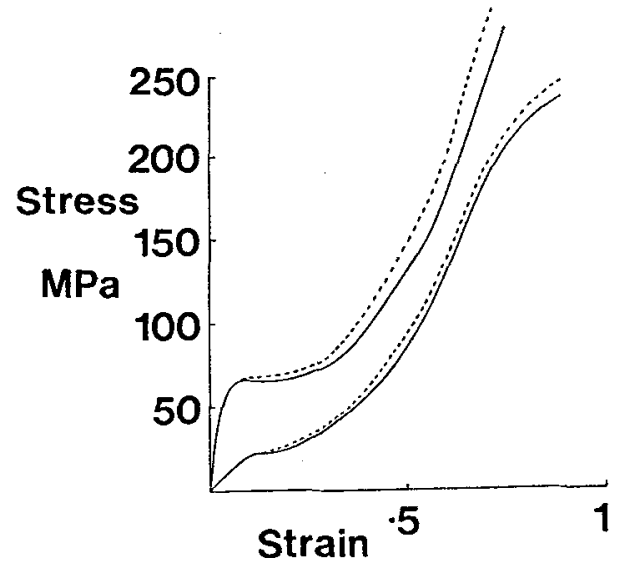

Figure 5 Experimental (- ${ }^{-}$) and isothermal (- - -) stress-strain curves. Upper curves PC; lower curves HDPE

Using the calculated decomposition rates, taking the maximum observed temperature as the relevant parameter, and assuming that the decomposition time is approximately equal to the time taken for a crack to run through a $1000 \mu \mathrm{m}$ region ahead of the crack tip (which corresponds to the typical length of a crazed region ahead of a crack in polymers) it is calculated that up to $10 \%$ of the volume of the region ahead of the crack is composed of voids formed by the thermal decomposition of the polymer into gases of low molecular weight. This voiding would be expected to have a considerable influence on craze formation and hence further crack propagation. For materials which did not exhibit cracking the temperatures achieved were not sufficient to cause appreciable decomposition despite the much larger duration of these bulk temperature rises (up to $500 \mu \mathrm{s}$ compared to the estimated $2 \mu \mathrm{s}$ for PC).

\section{CONCLUSIONS}

Two main points emerge from the work described in this paper. The first is that temperature rises in polymers with a high yield stress are sufficiently high, even at relatively low strains, to considerably change the experimentally determined stress strain curve from its isothermal value. The second is that temperature rises ahead of cracks in materials such as PC, PEK, PEEK are likely to be sufficiently high to cause decomposition ahead of a crack and so contribute to the formation of craze like regions and voids which may act as craze initiators as described by Michler /9/. Further investigations into these effects are being carried out. 
Table 1

Temperature Rise for the Polymers

\begin{tabular}{|c|c|c|c|c|c|}
\hline \multirow{3}{*}{ Polymer } & \multicolumn{2}{|c|}{ Bulk Temperature Rises ${ }^{\circ} \mathrm{C}$} & \multirow{3}{*}{$\begin{array}{l}\text { Measured } \\
\text { (Thermocouple) } \\
\quad \pm 3^{\circ} \mathrm{C}\end{array}$} & \multirow{2}{*}{\multicolumn{2}{|c|}{$\begin{array}{l}\text { Measured } \\
\text { (Film) } \\
\pm 50 \text { oC }\end{array}$}} \\
\hline & $\begin{array}{l}\text { Calculated } \\
\text { (No Fracture) } \\
\pm 5 \text { o C }\end{array}$ & $\begin{array}{l}\text { Calculated } \\
\text { (Fracture) } \\
\pm 5^{\circ} \mathrm{C}\end{array}$ & & & \\
\hline & & & & Bulk & Localised \\
\hline $\mathrm{PC}$ & 69 & 78 & 78 & $<200$ & 700 \\
\hline PEEK & 78 & 116 & 44 & - & 700 \\
\hline PEK & 99 & 177 & 64 & - & 700 \\
\hline HDPE & 38 & - & 34 & $<200$ & - \\
\hline PES & 66 & - & 50 & - & - \\
\hline NYLON 66 & 58 & - & 54 & 400 & - \\
\hline PP & 37 & - & 50 & 230 & - \\
\hline
\end{tabular}

Table 2

Decomposition Data for the Polymers

\begin{tabular}{lcll}
\hline Polymer & $\begin{array}{c}\text { E kJ mol-1 } \\
\pm 10 \%\end{array}$ & $\begin{array}{l}\text { A s-1 } \\
\pm 10 \%\end{array}$ & Decomposition Rate s-1 \\
\hline PEEK & 218 & $1.3 \times 10^{11}$ & 0.5 \\
PEK & 233 & $1 \times 10^{12}$ & 0.7 \\
HDPE & 310 & $3 \times 10^{19}$ & $2 \times 10^{-15}$ \\
NYLON 66 & 275 & $1 \times 10^{18}$ & $5 \times 10^{-4}$ \\
\hline
\end{tabular}

\section{ACKNOWLEDGEMENTS}

This work was supported by research grants from the SERC, a research fellowship from the Womens' Engineering Society (PCD), and some materials were kindly donated by ICI Wilton Materials Research Centre.

\section{REFERENCES}

/1/ Follansbee $\mathrm{P}$ S, Metallurgical applications of shock wave and high strain rate phenomena (Marcel Dekker, New York 1986) 607.

12/ Frost, H J and Ashby, M F, Deformation Maps (Pergamon Press, Oxford 1982).

13/ Walley, S M, Field, J E, Safford, N A, Proc 8th Intl Cof on Deformation Yield and Fracture of Polymers, Cambridge UK 1991.

/4/ Fuller, K N G, Fox, P G, Field, J E, Proc R Soc A341 (1974) 537-557.

15/ Swallowe, G M, Field, J E, Horn, L A, J Mat Sci 21 (1986) 4089-4096.

/6/ Heavens, S N and Field, J E, Proc R Soc A338 (1974) 77-93.

17/ Dixon, P R and Parry D J, Dymat '91, Strasbourg

181 ASTM E 698-79 (Reappred 1984).

19/ Michler, G H, J Mat Sci 25 (1990) 2321. 